\title{
Development of streamflow drought severity-duration-frequency curves using the threshold level method
}

\author{
J. H. Sung ${ }^{1}$ and E.-S. Chung ${ }^{2}$ \\ ${ }^{1}$ Ministry of Land, Infrastructure and Transport, Yeongsan River Flood Control Office, Gwangju, Republic of Korea \\ ${ }^{2}$ Department of Civil Engineering, Seoul National University of Science \& Technology, Seoul, 139-743, Republic of Korea \\ Correspondence to: E.-S. Chung (eschung@seoultech.ac.kr)
}

Received: 5 October 2013 - Published in Hydrol. Earth Syst. Sci. Discuss.: 3 December 2013

Revised: 16 July 2014 - Accepted: 22 July 2014 - Published: 3 September 2014

\begin{abstract}
This study developed a streamflow drought severity-duration-frequency (SDF) curve that is analogous to the well-known depth-duration-frequency (DDF) curve used for rainfall. Severity was defined as the total water deficit volume to target threshold for a given drought duration. Furthermore, this study compared the SDF curves of four threshold level methods: fixed, monthly, daily, and desired yield for water use. The fixed threshold level in this study is the 70th percentile value $\left(Q_{70}\right)$ of the flow duration curve (FDC), which is compiled using all available daily streamflows. The monthly threshold level is the monthly varying $Q_{70}$ values of the monthly FDC. The daily variable threshold is $Q_{70}$ of the FDC that was obtained from the antecedent 365 daily streamflows. The desired-yield threshold that was determined by the central government consists of domestic, industrial, and agricultural water uses and environmental in-stream flow. As a result, the durations and severities from the desired-yield threshold level were completely different from those for the fixed, monthly and daily levels. In other words, the desired-yield threshold can identify streamflow droughts using the total water deficit to the hydrological and socioeconomic targets, whereas the fixed, monthly, and daily streamflow thresholds derive the deficiencies or anomalies from the average of the historical streamflow. Based on individual frequency analyses, the SDF curves for four thresholds were developed to quantify the relation among the severities, durations, and frequencies. The SDF curves from the fixed, daily, and monthly thresholds have comparatively short durations because the annual maximum durations vary from 30 to 96 days, whereas those from the desired-yield threshold have much longer durations of up to 270 days. For the additional analysis, the return-period-duration curve was
\end{abstract}

also derived to quantify the extent of the drought duration. These curves can be an effective tool to identify streamflow droughts using severities, durations, and frequencies.

\section{Introduction}

The rainfall deficiencies of sufficient magnitude over prolonged durations and extended areas and the subsequent reductions in the streamflow interfere with the normal agricultural and economic activities of a region, which decreases agriculture production and affects everyday life. Dracup et al. (1980) defined a drought using the following properties: (1) nature of water deficit (e.g., precipitation, soil moisture, or streamflow); (2) basic time unit of data (e.g., month, season, or year); (3) threshold to distinguish low flows from high flows while considering the mean, median, mode, or any other derived thresholds; and (4) regionalization and/or standardization. Based on these definitions, various indices were proposed over the years to identify drought. Recent studies have focused on such multi-faceted drought characteristics using various indices (Palmer, 1965; Rossi et al., 1992; McKee et al., 1993; Byun and Wilhite, 1999; Tsakiris et al., 2007; Pandey et al., 2008a, b, 2010; World Meteorological Organization, 2008; Nalbantis and Tsakiris, 2009; Wang et al., 2011; Tabari et al., 2013; Tsakiris et al., 2013).

The American Meteorological Society (1997) groups the drought definitions and types into four categories: meteorological or climatological, agricultural, hydrological, and socioeconomic droughts. The meteorological drought is a result of the absence or reduction of precipitation and shortterm dryness results in an agricultural drought that severely 
reduces crop yields. Precipitation deficits over a prolonged period that reduce streamflow, groundwater, reservoir, and lake levels result in a hydrological drought. If hydrological droughts continue until the supply and demand of numerous economic goods are damaged, a socioeconomic drought occurs (Heim Jr., 2002).

Hydrological and socioeconomic droughts are notably difficult to approach. Nalbantis and Tsakiris (2009) defined a hydrological drought as "a significant decrease in the availability of water in all its forms, appearing in the land phase of the hydrological cycle". These forms are reflected in various hydrological variables such as streamflows, which include snowmelt and spring flow, lake and reservoir storage, recharge of aquifers, discharge from aquifers, and baseflow (Nalbantis and Tsakiris, 2009). Therefore, Tsakiris et al. (2013) described that streamflow is the key variable in describing hydrological droughts because it considers the outputs of surface runoff from the surface water subsystem, subsurface runoff from the upper and lower unsaturated zones, and baseflow from the groundwater subsystem. Furthermore, streamflow crucially affects the socioeconomic drought for several water supply activities such as hydropower generation, recreation, and irrigated agriculture, where crop growth and yield largely depends on the water availability in the stream (Heim Jr., 2002). Hence, hydrological and socioeconomic droughts are related to streamflow deficits with respect to hydrologically normal conditions or target water supplies for economic growth and social welfare.

For additional specification, Tallaksen and van Lanen (2004) defined a streamflow drought as a "sustained and regionally extensive occurrence of below average water availability". Thus, threshold level approaches, which define the duration and severity of a drought event while considering the daily, monthly, seasonal, and annual natural runoff variations, are widely applied in drought analyses (Yevjevich, 1967; Sen, 1980; Dracup et al., 1980; Dalezios et al., 2000; Kjeldsen et al., 2000; American Meteorological Society, 1997; Hisdal and Tallaksen, 2003; Wu et al., 2007; Pandey et al., 2008a; Yoo et al., 2008; Tigkas et al., 2012; van Huijgevoort et al., 2012). These approaches provide an analytical interpretation of the expected availability of river flow; a drought occurs when the streamflow falls below the threshold level. This level is frequently considered a certain percentile flow for a specific duration and assumed to be steady during the considered month, season, or year. Therefore, Kjeldsen et al. (2000) applied three variable threshold level methods using seasonal, monthly, and daily streamflows.

There has been a growing need for new planning and design of natural resources and environment based on the aforementioned scientific trends. For design purposes, rainfall intensity-duration-frequency (IDF) curves have been used for a long time to synthesize the design storm. Therefore, many studies have integrated drought severity and duration based on the multivariate theory (Bonaccorso et al., 2003; González

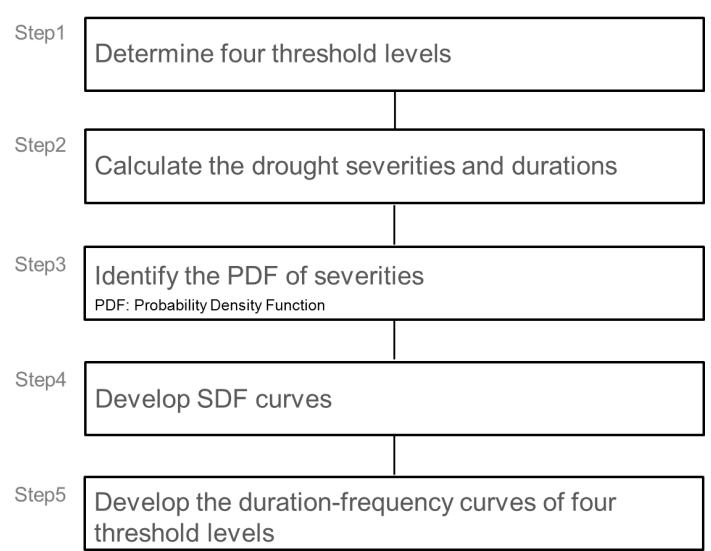

Figure 1. Procedure in this study.

and Valdés, 2003; Mishra and Singh, 2009; Song and Singh, 2010a, b; De Michele et al., 2013). However, these studies cannot fully explain droughts without considering the frequency, which resulted in the development of drought isoseverity curves for certain return periods and durations for design purposes.

Thus, based on the typical drought characteristics (water deficit and duration) and threshold levels, this study developed quantitative relations among drought parameters, namely, severity, duration, and frequency. This study quantified the streamflow drought severity, which is closely related to hydrological and socioeconomic droughts, using fixed, monthly, daily, and desired-yield threshold levels. Furthermore, this study proposed a streamflow SDF curve using the traditional frequency analyses. In addition, this study also developed duration frequency curves of four threshold levels from the occurrence probabilities of various duration events using a general frequency analysis because the deficit volume is not sufficient to explain the extreme droughts. This framework was applied to the Seomjin River basin in South Korea.

\section{Methodology}

\subsection{Procedure}

This study consists of five steps as shown in Fig. 1. Step 1 determines the threshold levels for the fixed, monthly, daily, and desired-yield levels for water use. The threshold selection description is shown in Sect. 2.3. Step 2 calculates the severities (total water deficits) and durations for all drought events at the four threshold levels. The method to derive the severity and duration is shown in Sect. 2.2. Step 3 derives the annual maxima of severity and duration and identifies the bestfit probability distribution functions using the L-moment ratio diagrams (Hosking and Wallis, 1997). The calculation procedure is shown in Sect. 2.4 using related equations and 


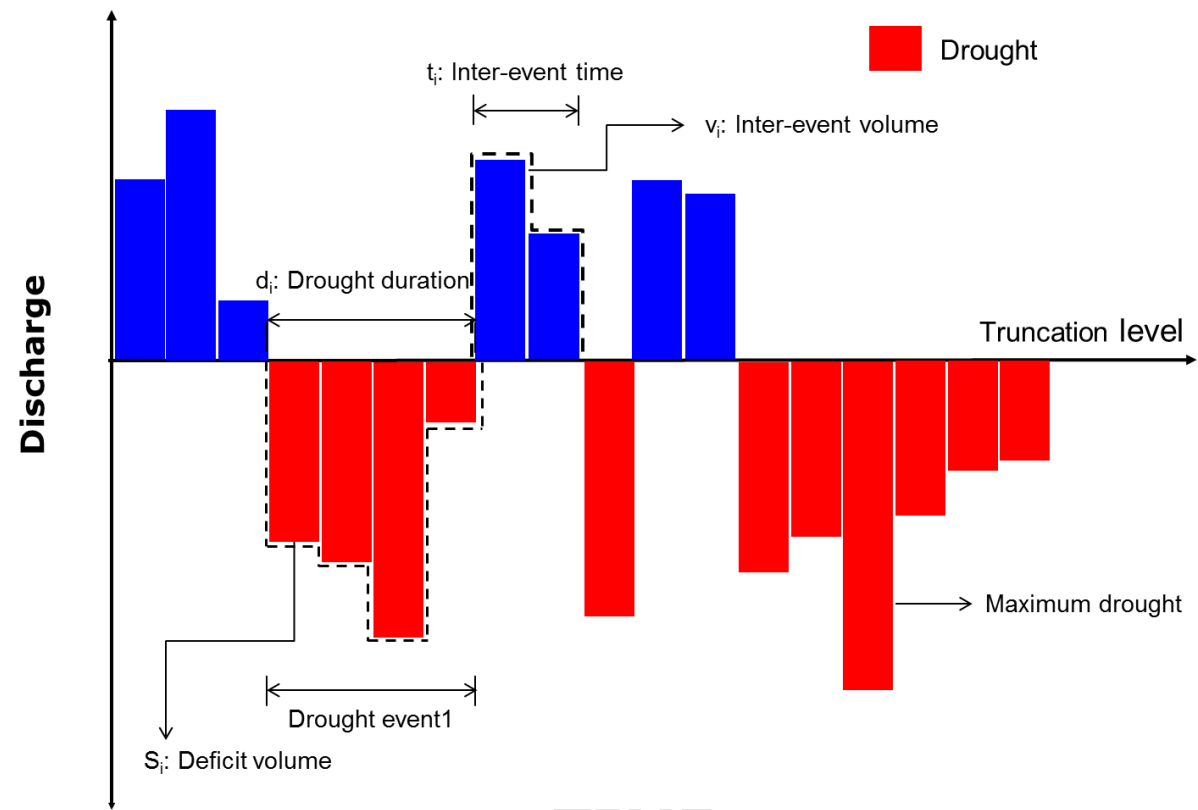

TIME

Figure 2. Definition sketch of a general drought event.

descriptions. Step 4 calculates the streamflow drought severities using the selected probability distribution with the bestfit parameters and develops the SDF curves. This step is described in Sect. 2.5. Step 5 develops the duration-frequency curves of the four threshold levels using an appropriate probability distribution.

\subsection{Streamflow drought severity}

In temperate regions where the runoff values are typically larger than zero, the most widely used method to estimate a hydrological drought is the threshold level approach (Yevjevich, 1967; Fleig et al., 2006; Tallaksen et al., 2009; Van Loon and Van Lanen, 2012). The streamflow drought severity with the threshold level method has the following advantages over the standardized precipitation index (SPI) in meteorology (Yoo et al., 2008) and the Palmer drought severity index (PDSI) in meteorology and agriculture (Dalezios et al., 2000): (1) no a priori knowledge of probability distributions is required, and (2) the drought characteristics such as frequency, duration, and severity are directly determined if the threshold is set using drought-affected sectors.

A sequence of drought events can be obtained using the streamflow and threshold levels. Each drought event is characterized by its duration $D_{i}$, deficit volume (or severity) $S_{i}$, and time of occurrence $T_{i}$ as shown by the definition sketch in Fig. 2. With a prolonged dry period, the long drought spell is divided into several minor drought events. Because these droughts are mutually dependent, Tallaksen et al. (1997) proposed that an independent sequence of drought events must be described using some type of pooling as described below.
If the "inter-event" time $t_{i}$ between two droughts of duration $d_{i}$ and $d_{i+1}$ and severity $s_{i}$ and $s_{i+1}$, respectively, are less than the predefined critical duration $t_{\mathrm{c}}$ and the preallowed inter-event excess volume $z_{\mathrm{c}}$, then the mutually dependent drought events are pooled to form a drought event as (Zelenhasic and Salvai, 1987; Tallaksen et al., 1997)

$d_{\text {pool }}=d_{i}+d_{i+1}+t_{\mathrm{c}}$

This study assumed $t_{\mathrm{c}}=3$ days and $z_{\mathrm{c}}=10 \%$ of $d_{i}$ or $d_{i+1}$ for simplicity.

\subsection{Threshold selection}

The threshold may be fixed or vary over the course of a year. A threshold is considered fixed if a constant value is used for the entire series and variable if it varies over the year based on the monthly and daily variable levels (Hisdal and Tallaksen, 2003). If the threshold is derived from the flow duration curve (FDC), the entire streamflow record is used in its derivation. As shown in Fig. 3, which is obtained from the study area, fixed and monthly thresholds can be obtained from an FDC and twelve monthly FDCs based on the entire record period. The daily varying threshold can be derived using the antecedent 365-day streamflow.

The threshold choice is influenced by the study objective, region, and available data. In general, a percentile of the data can be used as the threshold. Relatively low thresholds in the range of $Q_{70}-Q_{95}$ are often used for perennial rivers (Kjeldsen et al., 2000). The fixed threshold level in this study 

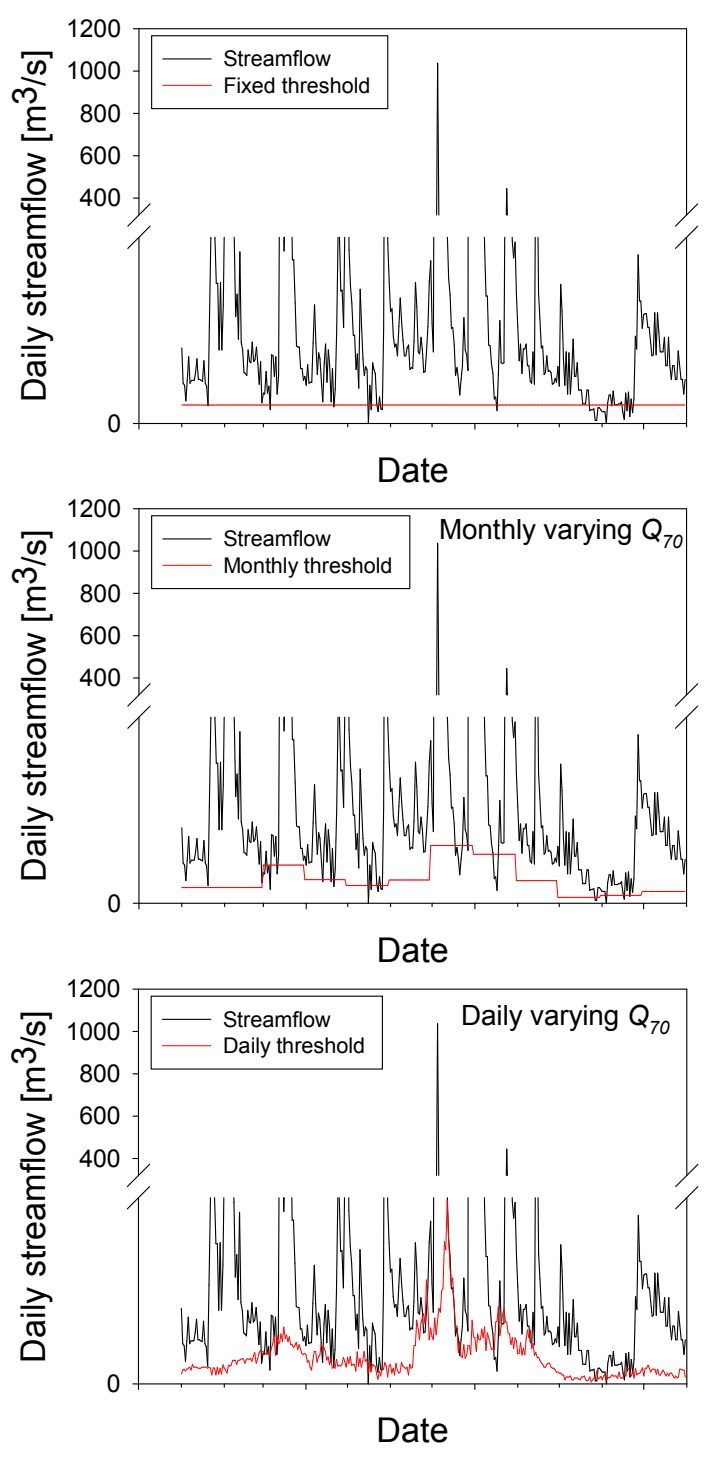

Figure 3. Examples of threshold levels: fixed (top panel), monthly varying (middle panel), and daily varying (bottom panel).

is the 70th percentile value $\left(Q_{70}\right)$ of FDC, which is compiled using all available daily streamflows, and the monthly threshold level is the monthly varying $Q_{70}$ s of each month's FDC. The daily variable threshold is the $Q_{70}$ value of the FDC, which is obtained from the antecedent 365 daily streamflows. However, the threshold selection should be further analyzed because it is not clear that $Q_{70}$ should be used as a representative threshold for rivers in a monsoon climate.

The time resolution, i.e., whether to apply a series of annual, monthly, or daily streamflows, depends on the hydrologic regime in the region of interest. In a temperate zone, a given year may include both severe droughts (seasonal droughts) and months with abundant streamflow, which indicates that the annual data do not often reveal severe droughts. Dry regions are more likely to experience droughts that last for several years, i.e., multi-year droughts, which supports the use of a monthly or annual time step. Hence, different time resolutions may lead to different results regarding the drought event selection. This study used the daily streamflow data, and various time resolutions $(30,60,90,120,150$, $180,210,240$, and 270 days) were selected to identify the temporal characteristics.

The variable threshold approach is adapted to detect streamflow deviations for both high- and low-flow seasons. Lower than average flows during high-flow seasons may be important for later drought development. However, periods with relatively low flow either during the high-flow season, which can be caused by a delayed onset of a snowmelt flood, are not commonly considered a drought. Therefore, the events that are defined with the varying threshold should be called streamflow deficiencies or streamflow anomalies instead of streamflow droughts (Hisdal et al., 2004). In contrast, the desired yield for sufficient water supply and environmental in-stream flow can be an effective method to identify a streamflow drought by considering hydrological and socioeconomic demands because environmental in-stream flow has become important in recent years.

\subsection{Probability distribution function}

An L-moment diagram for various goodness-of-fit techniques was used to evaluate the best probability distribution function for data sets in several recent studies (Hosking, 1990; Chowdhury et al., 1991; Vogel and Fennessey, 1993; Hosking and Wallis, 1997). The L-moment ratio diagram is a graph where the sample L-moment ratios, L-skewness $\left(\tau_{3}\right)$, and L-kurtosis $\left(\tau_{4}\right)$ are plotted as a scatterplot and compared with the theoretical L-moment ratio curves of the candidate distributions. The L-moment ratio diagrams were suggested as a useful graphical tool to discriminate amongst candidate distributions for a data set (Hosking and Wallis, 1997). The sample average and line of best fit were used to select statistical distributions, and they can be plotted on the same graph to select the best-fit distribution.

When plotting an L-moment ratio diagram, the relation among the parameters and the L-moment ratios $\tau_{3}$ and $\tau_{4}$ for several distributions are required. For a generalized extreme value (GEV) distribution, the three-parameter GEV distribution described by Stedinger et al. (1993) has the following probability density function (PDF, $f(x)$ ) and cumulative distribution function (CDF, $F(x))$ :

$$
\begin{aligned}
f(x) & =\frac{1}{\alpha}\left\{1-\frac{\kappa}{\alpha}(x-\xi)\right\}^{1 / \kappa-1} \\
\cdot & \exp \left[-\left\{1-\frac{\kappa}{\alpha}(x-\xi)\right\}^{1 / k}\right] \quad \kappa \neq 0, \\
f(x)= & \frac{1}{\alpha} \exp \left\{-\frac{x-\xi}{\alpha}-\exp \left(-\frac{x-\xi}{\alpha}\right)\right\} \quad \kappa=0, \\
F(x) & =\exp \left[-\left\{1-\frac{\kappa}{\alpha}(x-\xi)\right\}^{1 / \kappa}\right] \quad \kappa \neq 0,
\end{aligned}
$$




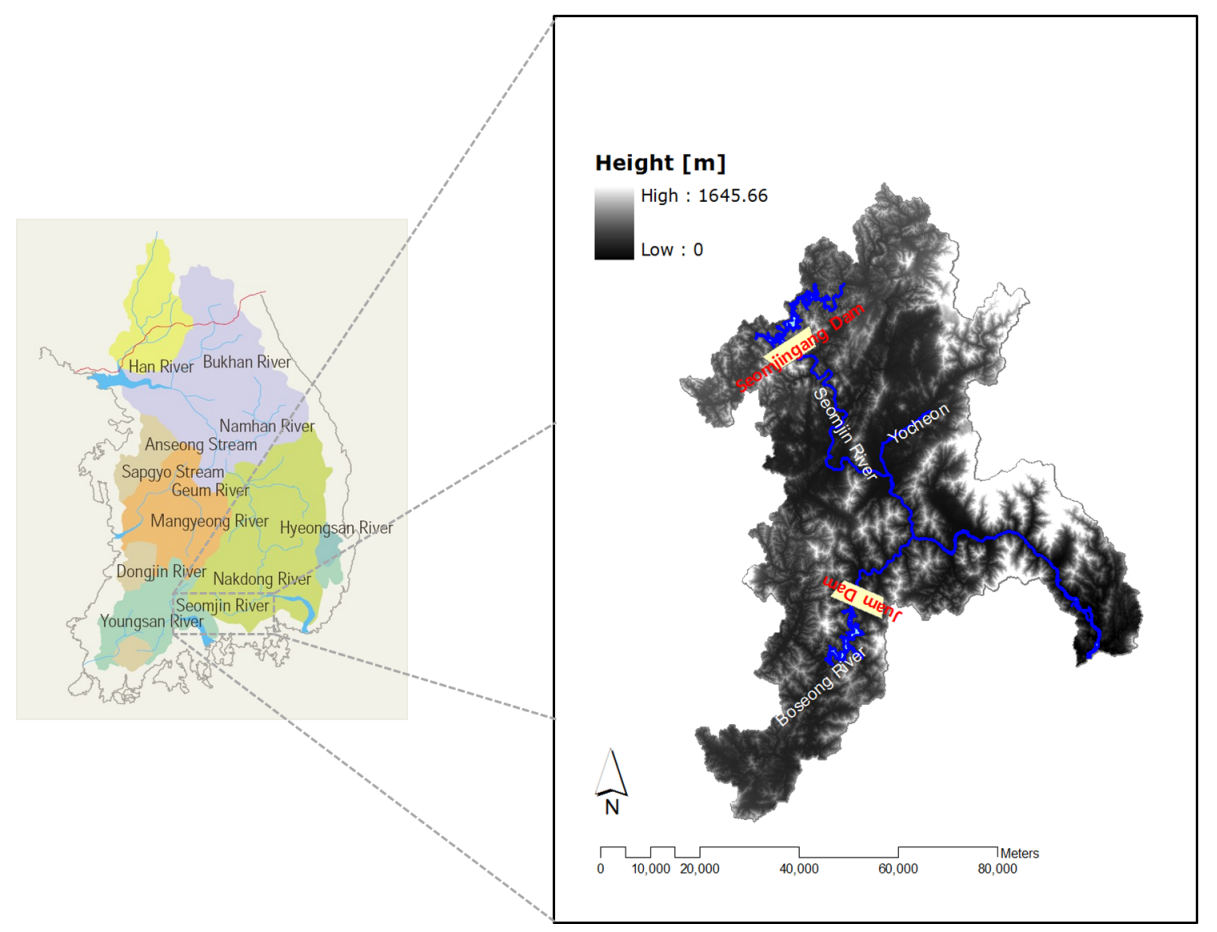

Figure 4. Location of the selected river basin, including elevation and rivers.

$F(x)=\exp \left\{-\exp \left(-\frac{x-\xi}{\alpha}\right)\right\} \quad \kappa=0$

where $\xi+\alpha / \kappa \leq x \leq \infty$ for $\kappa<0,-\infty \leq x \leq \infty$ for $\kappa=0$, and $-\infty \leq x \leq \xi+\alpha / \kappa$ for $\kappa>0$. Here, $\xi$ is a location, $\alpha$ is a scale, and $\kappa$ is a shape parameter. For $\kappa=0$, the GEV distribution reduces to the classic Gumbel (EV1) distribution with $\tau_{3}=0.17$. Hosking and Wallis (1997) provided more detailed information regarding the GEV distribution. The relation among the parameters and $\tau_{3}$ and $\tau_{4}$ for the GEV distribution of the shape parameters can be obtained as follows (Hosking and Wallis, 1997):

$$
\begin{aligned}
\tau_{3} & =\frac{2\left(1-3^{-\kappa}\right)}{\left(1-2^{-\kappa}\right)}-3 \\
\tau_{4} & =\frac{5\left(1-4^{-\kappa}\right)-10\left(1-3^{-\kappa}\right)+6\left(1-2^{-\kappa}\right)}{\left(1-2^{-\kappa}\right)} .
\end{aligned}
$$

\subsection{Development of the SDF relationships}

The IDF or depth-duration-frequency (DDF) curves can be defined to "allow calculation of the average design rainfall intensity (or depth) for a given exceedance probability over a range of durations" (Stedinger et al., 1993). Statistical frequency analyses such as rainfall analyses are frequently used for drought events. However, this method cannot fully explain droughts without considering the severity and duration, which resulted in the development of the SDF curve. Thus, extreme drought events can be specified using the frequency, duration, and either depth or mean intensity (i.e., severity). The frequency is usually described by the return period of the drought. Because its magnitude is given by the total depth that occurs in a particular duration, the SDF relation can be derived. To estimate the return periods of drought events of a particular depth and duration, the frequency distributions can be used (Dalezios et al., 2000).

\section{Study region}

The Seomjin River basin is located in southwestern Korea (Fig. 4). The area and total length of Seomjin River are approximately $4911.9 \mathrm{~km}^{2}$ and $212.3 \mathrm{~km}$, respectively. The altitude range is notably large, spanning from approximately 0 to $1646 \mathrm{~m}$ (Fig. 4). The climate of South Korea is characterized by extreme seasonal variations. Winter is cold and dry under the dominant influence of the Siberian air mass, whereas the summer is hot and humid with frequent heavy rainfalls, which are associated with the East Asian monsoon. In the Seomjin River basin, the measured precipitation is mainly concentrated in summer, and the measured mean annual precipitation varied from $<1350 \mathrm{~mm} \mathrm{yr}^{-1}$ (in the northern region) to $>1600 \mathrm{~mm} \mathrm{yr}^{-1}$ (in the southeastern region) during the 1975-2012 observation period. In general, approximately $60 \%$ of the annual precipitation occurs during the wet season (July through September) in South Korea. This extreme seasonality in the precipitation causes periodic shortages of 


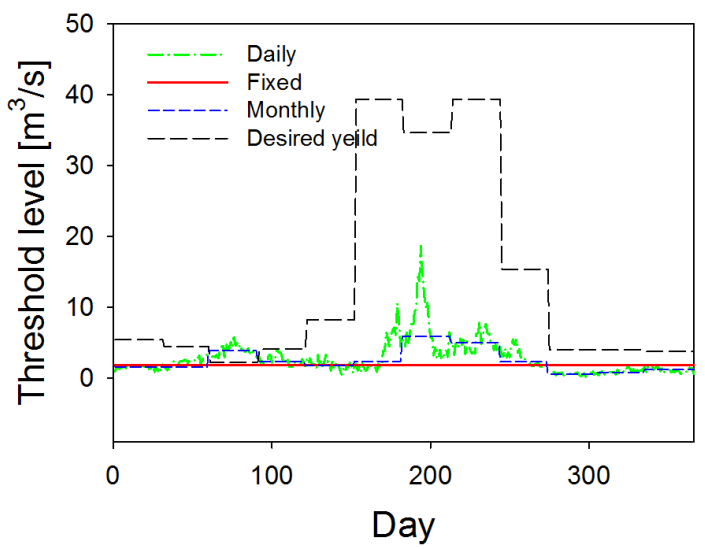

Figure 5. Comparison of the four threshold levels in this study.

water during the dry season (October through March) and flood damage during the wet season.

The administrative districts where the basin is located cover three provinces, four cities, and 11 counties (Namwon City, Jinan County, Imsil County, and Sunchang County in the northern Jeolla Province; Suncheon City, Gwangyang City, Damyang County, Gokseong County, Gurye County, Hwasun County, Boseong County, and Jangheung County in the southern Jeolla Province; and Hadong County in the southern Gyeongsang Province). The influx rates into the basin from these province are $47 \%$ (southern Jeolla Province), $44 \%$ (northern Jeolla Province), and 9\% (southern Gyeongsang Province), and a total of 321104 residents, who occupy 129322 households, live in these areas.

The land use consists of arable land $\left(876.29 \mathrm{~km}^{2}\right)$, forest land $\left(3400.61 \mathrm{~km}^{2}\right)$, urban area $\left(67.12 \mathrm{~km}^{2}\right)$, and other land uses $\left(567.86 \mathrm{~km}^{2}\right)$. Major droughts occurred in the southern Jeolla Province from 1967 to 1968 and from 1994 to 1995. The Seomjin River basin had $<1,000 \mathrm{~mm}$ of precipitation on average in 1977, 1988, 1994, and 2008. Among these years, the annual precipitation in 1988 was only $782.7 \mathrm{~mm}$ (56.5\%) of the annual average of $1385.5 \mathrm{~mm}$ from 1967 to 2008, which represents a severe drought.

\section{Results}

\subsection{Determination of the threshold levels}

This study used four threshold levels. The fixed threshold level is $Q_{70}$ of the FDC, which resulted from 37 year daily streamflows. The monthly thresholds are twelve $Q_{70}$ values of monthly FDCs, which incorporated the data of all daily streamflows from January to December for the past 37 years. The daily threshold is $Q_{70}$ of the FDCs, which resulted from the antecedent 365 daily streamflows. Thus, the daily threshold level smoothly varies everyday. The desired-yield threshold for a sufficient water supply and environmental in-stream flow was determined by the Korean central government. This
Table 1. Monthly average of the four threshold levels.

\begin{tabular}{lcccr}
\hline & \multicolumn{4}{c}{ Threshold level $\left[\mathrm{m}^{3} \mathrm{~s}^{-1}\right]$} \\
\cline { 2 - 5 } & Fixed & Monthly & Daily & Desired yield \\
\hline Jan & 1.9 & 1.6 & 1.5 & 5.4 \\
Feb & 1.9 & 1.6 & 2.4 & 4.5 \\
Mar & 1.9 & 3.9 & 3.9 & 2.2 \\
Apr & 1.9 & 2.4 & 2.5 & 4.1 \\
May & 1.9 & 1.8 & 1.9 & 8.2 \\
Jun & 1.9 & 2.4 & 3.4 & 39.4 \\
Jul & 1.9 & 5.9 & 7.1 & 34.7 \\
Aug & 1.9 & 5.0 & 5.1 & 39.4 \\
Sep & 1.9 & 2.3 & 2.9 & 15.4 \\
Oct & 1.9 & 0.6 & 0.7 & 4.0 \\
Nov & 1.9 & 0.8 & 0.9 & 4.0 \\
Dec & 1.9 & 1.2 & 1.2 & 3.8 \\
\hline
\end{tabular}

threshold is related to social and economic droughts because it associates the supply and demand of a number of economic goods and environmental safety. The desired-yield threshold is considerably different from the other levels and represents more realistic conditions because the desired yield is equivalent to the planned water supply.

The four calculated thresholds are presented in Fig. 5, and the specific monthly averaged values are listed in Table 1 . The average levels were $1.9,2.5,2.8$, and $13.8 \mathrm{~m}^{3} \mathrm{~s}^{-1}$ for the fixed, monthly, daily and desired-yield levels, respectively. The daily threshold levels, which significantly fluctuated because of the natural streamflow variations during the antecedent 365 days, were the largest among the four threshold levels because a summer period (June, July, and August) was considered. The desired-yield level was larger than the fixed, monthly, and daily thresholds. This phenomenon occurred during the winter in Korea, which significantly decreased both the water demand and natural runoff during the winter (December, January, and February). However, the thresholds for the daily, monthly, and desired-yield levels during the summer were much higher than those during the other seasons. The desired yield during May and June had much higher threshold levels than the other thresholds because this season had the highest agricultural water demand.

\subsection{Calculations of the streamflow drought severity and duration}

The durations and severities for all streamflow drought events were calculated based on the streamflow drought concept and threshold levels. The annual maxima values of duration and severity are shown in Fig. 6, and the summarized values are listed in Table 2. The maximum durations from the desired-yield threshold approach were considerably higher than those from the other thresholds because the desired yields were highest during June and July for agricultural 
(a) Duration.

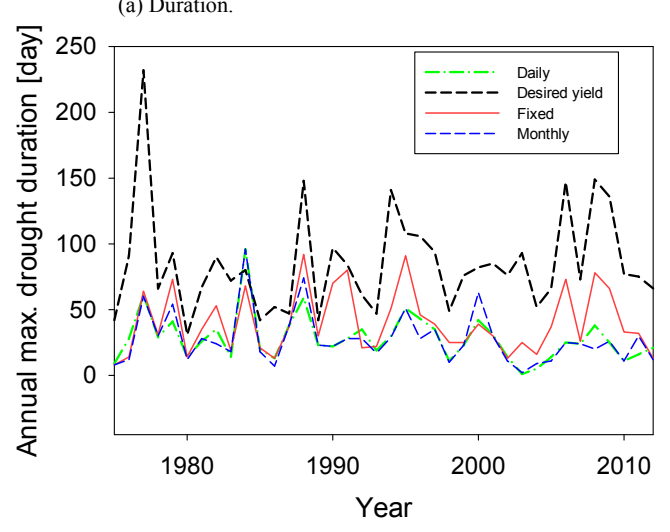

(b) Severity.

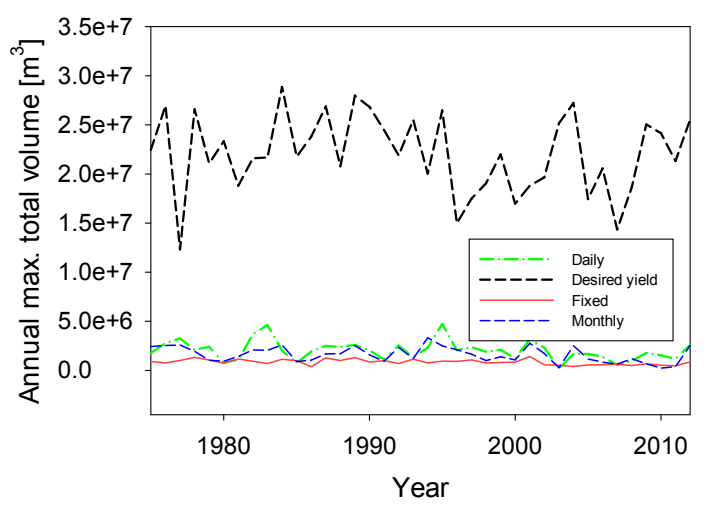

Figure 6. Time series of the annual maxima values of duration and severity.

water use. Similar to the results for the drought duration, the severities showed much higher values.

To compare the differences among the four threshold levels, the correlation coefficients among the water deficits from four different threshold levels were calculated as shown in Table 3. Similar trends were observed for the monthly and daily threshold levels. However, the durations and severities from the desired-yield threshold level were completely different from those for the fixed, monthly, and daily levels. In other words, the drought identification techniques based on general threshold levels cannot reflect the socioeconomic drought in terms of the water supply and demand. Therefore, two-way approaches that are categorized using the time periods (fixed, monthly, and daily) for hydrological drought and the desired-yield threshold for socioeconomic droughts should be separately included to identify specific drought characteristics.

\subsection{Determination of the probability distribution function}

The L-moment diagrams of various goodness-of-fit techniques were used to evaluate the best probability distribution function for the data sets. To develop a streamflow
Table 2. Summary of the four threshold approaches.

\begin{tabular}{lcr}
\hline $\begin{array}{l}\text { Threshold } \\
\text { level } \\
\text { method }\end{array}$ & $\begin{array}{r}\text { Maximum } \\
\text { duration } \\
\text { (days) }\end{array}$ & $\begin{array}{r}\text { Maximum } \\
\text { severity } \\
\left(\mathrm{m}^{3}\right)\end{array}$ \\
\hline Fixed & 92 & 9304762 \\
Monthly & 96 & 10774642 \\
Daily & 96 & 18457943 \\
Desired yield & 232 & 285854400 \\
\hline
\end{tabular}

Table 3. Correlations between the durations and the severities of the four threshold levels.

\begin{tabular}{lcccc}
\hline & Fixed & Monthly & Daily & Desired yield \\
\hline \multicolumn{5}{c}{ Duration } \\
\hline Fixed & 1 & & & \\
Monthly & 0.632 & 1 & & \\
Daily & 0.632 & 0.923 & 1 & 1 \\
Desired yield & 0.677 & 0.420 & 0.475 & \\
\hline \multicolumn{5}{c}{ Severity } \\
Fixed & 1 & & & \\
Monthly & 0.441 & 1 & & 1 \\
Daily & 0.414 & 0.853 & 1 & \\
Desired yield & 0.281 & 0.551 & 0.599 & \\
\hline
\end{tabular}

drought SDF curve, the proper probability distribution function should be determined based on the statistical results as described in Sect. 2.4.

The L-moment ratio diagrams were derived for the four threshold approaches and are shown in Fig. 7. Among the examined distribution models, three parameter distributions (the Pearson Type 3 (PT3), Generalized Normal (GNO), and GEV distributions) appeared consistent with their data sets. In the frequency analysis that addressed extreme values, the distributions that use three parameters were required to express the upper tail. The PT3, GNO, and GEV distributions can be applied in this study. As shown in Fig. 7, this study selected the GEV distribution for a representative probability distribution because most observations are appropriate for the GEV.

\subsection{Development of SDF curves}

Streamflow drought SDF curves were developed using the derived probability distribution functions as shown in Fig. 8. The SDF curves described the streamflow drought severities with respect to durations and frequencies. The severity increases with increasing frequency and duration. For these plots, 10-, 20-, 50-, 80-, and 100-year-frequency severities were calculated at 30-, 60-, 90-, 120-, 150-, 180-, 210, and 270-day durations. Because the amount of available data only corresponds to 37 years, we calculated up to a 
(a) Fixed.

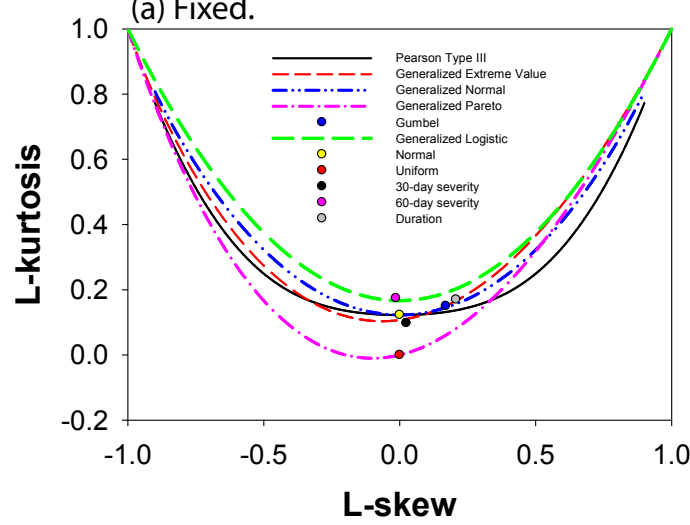

(b) Daily.

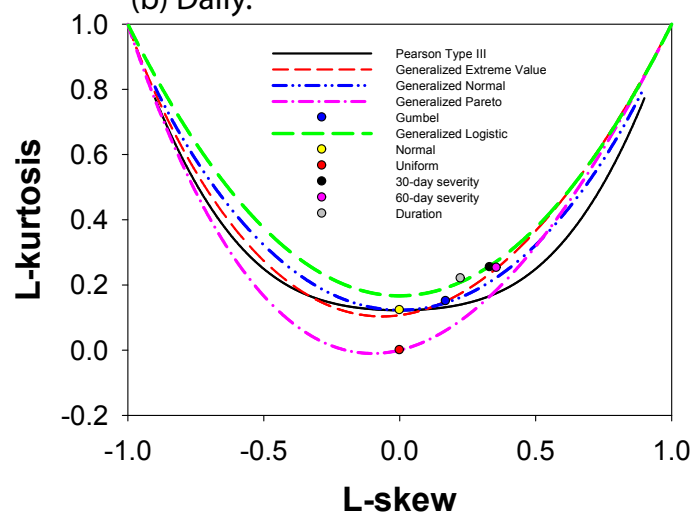

(c) Monthly.

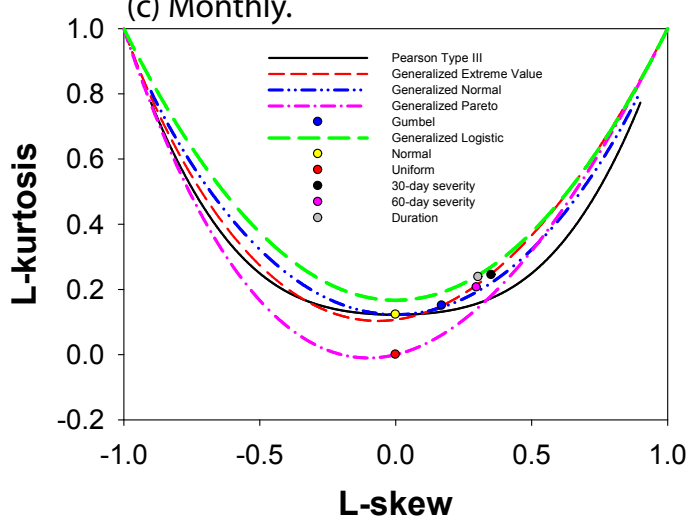

(c) Desired yield.

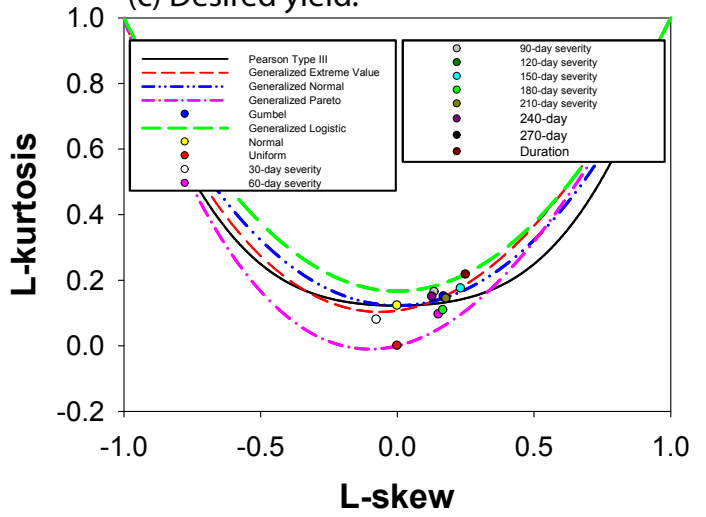

Figure 7. L-moment diagram to identify the probability distribution.
Table 4. Severity-duration-frequency of the desired yield in the Seomjin River basin.

\begin{tabular}{lrrrrr}
\hline Duration & \multicolumn{5}{c}{ Return period [yr] } \\
\cline { 2 - 6 } [day] & 10 & 20 & 50 & 80 & 100 \\
\hline 30 & 60.7 & 66.4 & 73.1 & 75.9 & 77.2 \\
60 & 82.4 & 95.9 & 112.5 & 120.8 & 124.9 \\
90 & 95.6 & 112.8 & 133.7 & 144.6 & 149.3 \\
120 & 106.8 & 132.7 & 170.0 & 189.7 & 200.1 \\
150 & 116.6 & 145.2 & 186.6 & 208.7 & 220.3 \\
180 & 126.0 & 155.5 & 197.5 & 220.8 & 231.7 \\
210 & 134.3 & 168.7 & 217.7 & 243.1 & 257.6 \\
240 & 141.0 & 174.2 & 223.9 & 248.8 & 261.3 \\
270 & 144.6 & 182.0 & 233.3 & 258.9 & 272.9 \\
\hline
\end{tabular}

100-year frequency. However, the SDF curves from the fixed, daily, and monthly thresholds were calculated using comparatively short durations because the annual maximum durations vary from 30 to 96 days. Nonetheless, the SDF curve from the desired-yield levels showed the water deficits for much longer durations of 30-270 days. In addition, the water deficits from the desired-yield levels are much higher than those from other levels even for the same duration.

For a specific description, Table 4 compares all severities to specific frequencies and durations for the desiredyield threshold. When the duration increases, the severity differences among the return periods significantly increase. Therefore, because the streamflow drought severity should be more crucial when the drought continues for a longer period, the frequency of long droughts should be approached with caution.

\subsection{Development of duration-frequency curve}

Using the same traditional frequency analysis, the durationfrequency curves for four threshold levels were developed as shown in Fig. 9. In other words, the annual maxima durations are derived based on the four threshold level methods. As shown in the SDF relationship, the GEV distribution was selected from the L-moment ratio diagram. For these plots, 2-, 3-, 5-, 10-, 20-, 30-, 50-, 70-, 80-, and 100-year-frequency severities were calculated. Similar to the SDF curves, the durations for the desired-yield threshold were much higher than those for the other three thresholds.

\section{Summary and conclusions}

This study developed a useful concept to describe the characteristics of streamflow droughts using threshold level methods. The SDF curves for streamflow droughts were developed to quantify a specific volume based on a specific duration and frequency. This study compared the SDF curves of four threshold level methods: fixed, monthly, daily, and 
(a) Fixed.

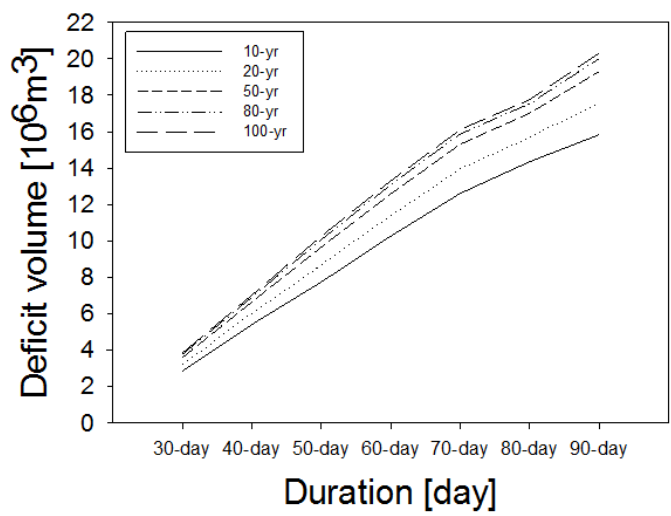

(c) Monthly.

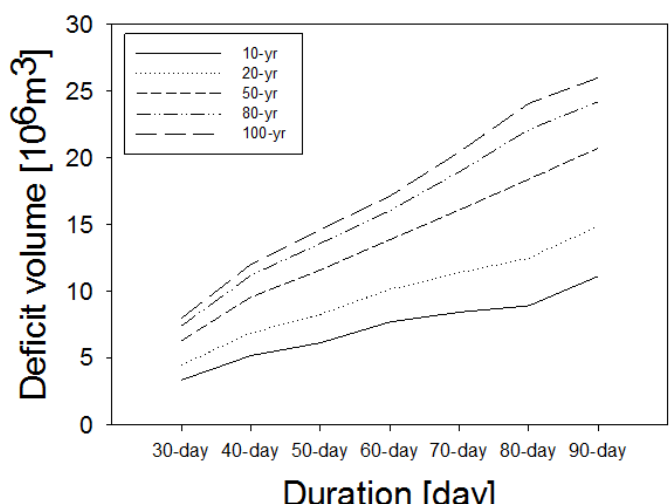

(b) Daily.

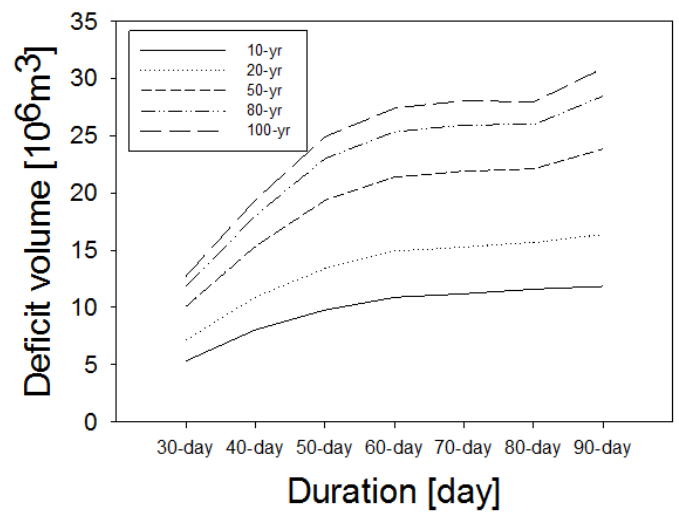

(d) Desired yield.

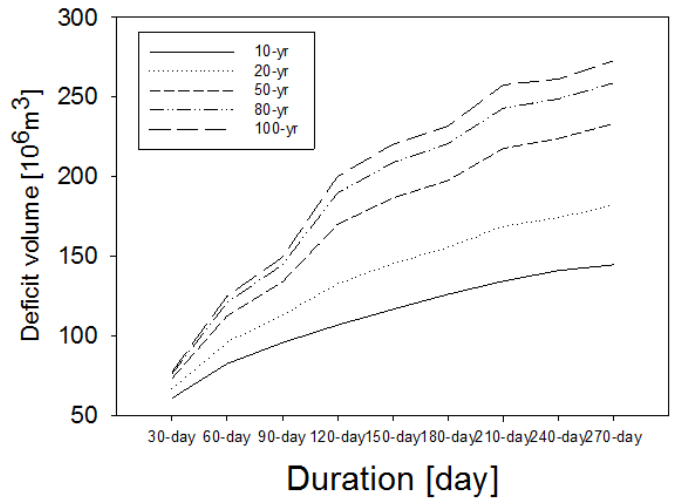

Figure 8. SDF curves of the four threshold approaches in the Seomjin River basin.

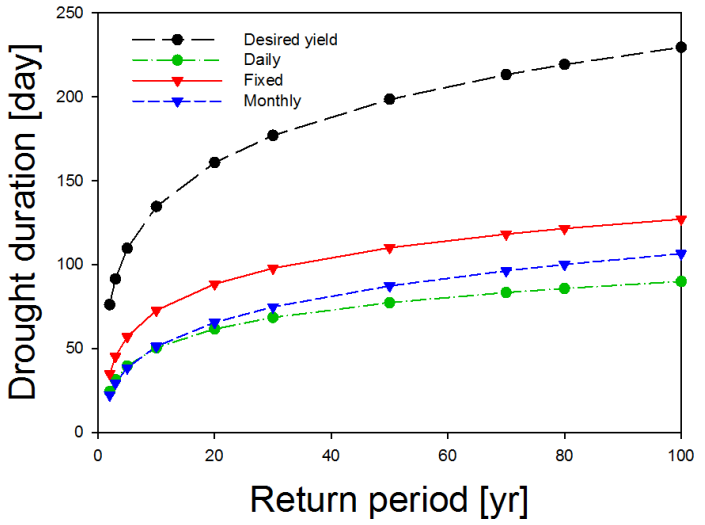

Figure 9. Duration-frequency curves of the four threshold level approaches in the Seomjin River basin.

desired-yield levels for water use. In addition, the durationfrequency curves for four thresholds were used to derive the relationship between the drought duration and the drought frequency. This study used the severity, which represents the total water deficit for specific durations. From this study, we can make the following conclusions:
1. The daily threshold levels significantly fluctuated because of the natural streamflow variations for the antecedent 365 days and were the largest threshold level because a summer period (June, July, and August) was considered. The desired-yield level was larger than the fixed, monthly, and daily thresholds. This phenomenon occurred during the winter in Korea; thus, both the water demand and natural runoff during the winter (December, January, and February) were notably small.

2. The durations and severities from the desired-yield threshold level were completely different from those for the fixed, monthly, and daily levels. In other words, the desired-yield threshold can identify streamflow droughts using the total water deficit to the hydrological and socioeconomic targets, whereas the fixed, monthly, and daily streamflow thresholds derive the deficiencies or anomalies from the average of historical streamflow.

3. The GEV distribution for a representative probability distribution was selected for the streamflow drought severities because most observations are appropriate for the GEV. 
4. The severities increased with increasing duration and frequency. However, these values were notably different because the four threshold level approaches defined the streamflow drought differently. The SDF curves from the fixed, daily, and monthly thresholds were calculated using comparatively short durations because the annual maximum durations vary from 30 to 96 days. However, the SDF curve from the desired-yield levels shows the water deficits for longer durations of 30-270 days. In addition, the water deficits from the desired-yield levels are significantly higher than those from the others even in the same duration.

5. For the SDF curve of the desired-yield threshold, when the duration increases, the severity differences among return periods significantly increase. Therefore, because the streamflow drought severity should be more crucial when the drought continues for a longer period, the frequency of long droughts should be approached with caution.

6. Duration-frequency curves for four threshold levels were also developed to quantify the streamflow drought duration. Similar to the SDF curves, the desired-yield level had much longer durations for the other three thresholds.

7. In the end, the drought identification techniques based on the general threshold levels cannot reflect the socioeconomic drought in terms of water supply and demand. Therefore, the two-way approaches that are categorized by the time periods (fixed, monthly, and daily) for hydrological drought and the desired-yield threshold for socioeconomic drought should be separately included to identify specific drought characteristics.

The streamflow drought SDF curves that were developed in this study can be used to quantify the water deficit for natural streams and reservoirs. In addition, these curves will be extended to allow for regional frequency analyses, which can estimate the streamflow drought severity at ungauged sites. Therefore, they can be an effective tool to identify any streamflow droughts using the severity, duration, and frequency.

Acknowledgements. This study was supported by funding from the Basic Science Research Program of the National Research Foundation of Korea (2010-0010609).

Edited by: C. De Michele

\section{References}

American Meteorological Society: Meteorological drought - Policy statement, B. Am. Meteorol. Soc., 78, 847-849, 1997.

Bonaccorso, B., Cancelliere, A., and Rossi, G.: An analytical formulation of return period of drought severity, Stoch. Environ. Res. Risk A., 17, 157-174, 2003.

Byun, H.-R. and Wilhite, D. A.: Objective quantification of drought severity and duration, J. Climate, 12, 747-756, 1999.

Chowdhury, J. U., Stedinger, J. R., and Lu, L.-H.: Goodness-of-fit tests for regional generalized extreme value flood distributions, Water Resour. Res., 27, 1765-1776, 1991.

Dalezios, N., Loukas, A., Vasiliades, L., and Liakopolos, E.: Severity-duration-frequency analysis of droughts and wet periods in Greece, Hydrolog. Sci. J., 45, 751-769, 2000.

De Michele, C., Salvadori, G., Vezzoli, R., and Pecora, S.: Multivariate assessment of droughts: Frequency analysis and dynamic return period, Water Resour. Res., 49, 6985-6994, 2013.

Dracup, J. A., Lee, K. S., and Paulson Jr., E. G.: On the statistical characteristics of drought events, Water Resour. Res., 16, 289296, 1980.

Fleig, A. K., Tallaksen, L. M., Hisdal, H., and Demuth, S.: A global evaluation of streamflow drought characteristics, Hydrol. Earth Syst. Sci., 10, 535-552, doi:10.5194/hess-10-535-2006, 2006.

González, J. and Valdés, J. B.: Bivariate drought recurrence analysis using tree ring reconstructions, J. Hydrol. Eng., 8, 247-258, 2003.

Heim Jr., R. R.: A review of twentieth-century drought indices used in the United States, B. Am. Meteorol. Soc., 83, 1149-1165, 2002.

Hisdal, H. and Tallaksen, L. M.: Estimation of regional meteorological and hydrological drought characteristics: A case study for Denmark, J. Hydrol., 281, 230-247, 2003.

Hisdal, H., Tallaksen, L. M., Clausen, B., and Alan, E. P.: Ch. 5 Hydrological drought characteristics, in: Hydrological Droughts: Processes and Estimation Methods for Streamflow and Groundwater, Developments in Water Science, Elsevier, Amsterdam, 139-198, 2004.

Hosking, J. R. M.: L-moments: Analysis and estimation of distributions using linear combinations of order statistics, J. Roy. Stat. Soc. Ser. B, 52, 105-124, 1990.

Hosking, J. R. M. and Wallis, J. R.: Regional Frequency Analysis: An Approach Based on L-Moments, Cambridge Univ. Press, New York, 1997.

Kjeldsen, T. R., Lundorf, A., and Dan, R.: Use of two component exponential distribution in partial duration modeling of hydrological droughts in Zimbabwean rivers, Hydrolog. Sci. J., 45, 285-298, 2000.

McKee, T. B., Doesken, N. J., and Kleist, J.: The relationship of drought frequency and duration to time scales, Proc. 8th Conf. Appl. Climatol., American Meteor. Soc., Boston, 179-184, 1993.

Mishra, A. K. and Singh, V. P.: Analysis of drought severity.area.frequency curves using a general circulation model and scenario uncertainty, J. Geophys. Res., 114, D06120, doi:10.1029/2008JD010986, 2009.

Nalbantis, I. and Tsakiris, G.: Assessment of hydrological drought revisited, Water Resour. Manage., 23, 881-897, 2009.

Palmer, W.C.: Meteorological drought, Research Paper No. 45, US Department of Commerce Weather Bureau, Washington, D.C., 1965. 
Pandey, R. P., Mishra, S. K., Singh, R., and Ramasastri, K. S.: Streamflow drought severity analysis of Betwa river system (INDIA), Water Resour. Manage., 22, 1127-1141, 2008a.

Pandey, R. P., Sharma, K. D., Mishra, S. K., Singh, R., and Galkate, R. V.: Assessing streamflow drought severity using ephemeral streamflow data, Int. J. Ecol. Econ. Stat., 11, 77-89, 2008b.

Pandey, R. P., Pandey, A., Galkate, R. V., Byun, H.-R., and Mal, B. C.: Integrating hydro-meteorological and physiographic factors for assessment of vulnerability to drought, Water Resour. Manage., 24, 4199-4217, 2010.

Rossi, G., Benedini, M., Tsakins, G., and Giakoumakis, S.: On regional drought estimation and analysis, Water Resour. Manage., 6, 249-277, 1992.

Sen, Z.: Statistical analysis of hydrologic critical droughts, J. Hydraul. Div.-ASCE, 106, 99-115, 1980.

Song, S. B. and Singh, V. P.: Frequency analysis of droughts using the Plackett copula and parameter estimation by genetic algorithm, Stoch. Environ. Res. Risk A., 24, 783-805, 2010a.

Song, S. B. and Singh, V. P.: Meta-elliptical copulas for drought frequency analysis of periodic hydrologic data, Stoch. Environ. Res. Risk A., 24, 425-444, 2010b.

Stedinger, J. R., Vogel, R. M., and Foufoula-Georgiou, E.: Frequency Analysis of Extreme Events, in: Chapter 18, Handbook of Hydrology, edited by: Maidment, D., McGraw-Hill, Inc., New York, 1993.

Tabari, H., Nikbakht, J., and Talaee, P. H.: Hydrological drought assessment in Northwestern Iran based on streamflow drought index (SDI), Water Resour. Manage., 27, 137-151, 2013.

Tallaksen, L. M. and van Lanen, H. A. J.: Hydrological drought: processes and estimation methods for streamflow and groundwater, Developments in Water Science, Elsevier Science B. V., Amsterdam, 2004.

Tallaksen, L. M., Madsen, H., and Clusen, B.: On the definition and modeling of streamflow drought duration and deficit volume, Hydrolog. Sci. J., 42, 15-33, 1997.

Tallaksen, L. M., Hisdal, H., and van Lanen, H. A. J.: Space-time modelling of catchment scale drought characteristics, J. Hydrol., $375,363-372,2009$.
Tigkas, D., Vangelis, H., and Tsakiris, G.: Drought and climatic change impact on streamflow in small watersheds, Sci. Total Environ., 440, 33-41, 2012.

Tsakiris, G., Pangalou, D., and Vangelis, H.: Regional drought assessment based on the Reconnaissance Drought Index (RDI), Water Resour. Manage., 21, 821-833, 2007.

Tsakiris, G., Nalbantis, I., Vangelis, H., Verbeiren, B., Huysmans, M., Tychon, B., Jacquemin, I., Canters, F., Vanderhaegen, S., Engelen, G., Poelmans, L., De Becker, P., and Batelaan, O.: A System-based Paradigm of Drought Analysis for Operational Management, Water Resour. Manage., 27, 5281-5297, 2013.

van Huijgevoort, M. H. J., Hazenberg, P., van Lanen, H. A. J., and Uijlenhoet, R.: A generic method for hydrological drought identification across different climate regions, Hydrol. Earth Syst. Sci., 16, 2437-2451, doi:10.5194/hess-16-2437-2012, 2012.

Van Loon, A. F. and Van Lanen, H. A. J.: A process-based typology of hydrological drought, Hydrol. Earth Syst. Sci., 16, 19151946, doi:10.5194/hess-16-1915-2012, 2012.

Vogel, R. M. and Fennessey, N. M.: L-moment diagrams should replace product moment diagrams, Water Resour. Res., 29, 17451752, 1993.

Wang, A., Lettenmaier, D. P., and Sheffield, J.: Soil moisture drought in China, 1950-2006, J. Climate, 24, 3257-3271, 2011.

World Meteorological Organization: Manual on Low-flow Estimation and Prediction, Operational Hydrology Report No. 50, Geneva, 2008.

Wu, J., Soh, L. K., Samal, A., and Chen, X. H.: Trend analysis of streamflow drought events in Nebraska, Water Resour. Manage., 22, 145-164, 2007.

Yevjevich, V.: An objective approach to definition and investigation of continental hydrological droughts, Hydrology Paper No. 23 , Colorado State University, Fort Collins, Colorado, USA, 1967.

Yoo, C., Kim, D., Kim, T. W., and Hwang, K. N.: Quantification of drought using a rectangular pulses Poisson process model, J. Hydrol., 355, 34-48, 2008.

Zelenhasic, E. and Salvai, A.: A method of streamflow drought analysis, Water Resour. Res., 23, 156-168, 1987. 